\title{
From audit to quality and beyond
}

\author{
A new journal for a crucial subject
}

Doctors in Britain have hummed and hawed over audit for years, but now everybody is supposed to be doing it. ${ }^{12}$ The audit machinery has been kick started with $£ 48 \mathrm{~m}$, and accreditation for training posts will be threatened if audit is not seen to be happening. Still, however, many doctors are far from clear about what exactly they should be doing, and some see audit as an administrative nuisance tacked on to an already overstuffed timetable. Yet debate over audit and quality is likely to change profoundly the practice of medicine.

To be effective audit needs to be a challenge. Too many doctors depend on unsystematic and uncritical single case note review, case presentations, or meetings on deaths and discharges: collecting and counting are not enough. ${ }^{3}$ Audit that improves quality must be systematic and critical, but it can be done without the large samples often needed for research and without large computerised databases.

The aim of audit is to produce change, and the editorial that announced the birth of our audit section emphasised the importance of "closing the feedback loop." "Without closure of the loop, the editorial said, audit may be "little more than a pious exercise in self congratulation." Yet a review of the papers that we have published in our audit section quickly shows that only a minority have closed the feedback loop: as always, the rhetoric is ahead of the reality. Getting doctors (or anybody) to change is hard work, but the changes that have been seen over a short period are encouraging. Failure to close the loop immediately should not depress doctors and should not be used as ammunition by audit cynics and audit dodgers.

Closing the feedback loop is only one way in which audit can improve patient care. Sitting down and agreeing standards may well produce benefits in themselves. There is a tension between nationally agreed guidelines and standards and those agreed locally, but doctors are more likely to buy into guidelines if they have helped draw them up. Debate over standards and guidelines is challenging everyone-generalists and specialists. ${ }^{56}$ Learning to share information and views on quality may also in itself raise quality, and audit will produce change only if the process extends beyond doctors to other health care workers and to managers.

Barriers to audit include our limited knowledge of outcomes and the effectiveness of many medical interventions and lack of information on what happens in routine medical practice. Another barrier is the narrowness of medical education and the poverty of training given to doctors after graduation. Teaching facts without explicitly demonstrating how much of medical practice is driven by habit and opinion is a tradition handed down to generations of students. Learning without critical appraisal of the subject matter is a shaky foundation for the future and does not provide the skills needed for medical audit.

Some doctors respond to audit as though it is about finding bad apples, but to be effective it must be about continuously improving the quality of health care offered by everybody..$^{7-10}$ Linking audit to postgraduate education will thus be essential.

The audit section of the journal has reflected the development of medical audit over the past 18 months, and slowly professional thinking on audit is becoming clearer. And this is a process happening all over the world. Over the next few months the $B M \mathcal{F}$ will carry a series of articles describing progress with audit in other countries. The whole profession needs to claim ownership of audit and see a constant search for improvement as a central part of being a doctor.

Now that the amount and quality of work being carried out as part of audit are improving the $B M F$ Publications Group is launching a new journal-Quality in Health Care (see p 208 and a call for papers facing p 210 in CR edition, inside back cover in GP edition, and on the back of the contents page in International edition). The journal will appear in March 1992, and the spring should also see a conference on quality in health care organised jointly by the new journal, the $B M \mathcal{F}$, the BMA, and the King's Fund Centre. In response to requests from members and readers and convinced that raising quality deserves a push the BMA and the $B M \mathcal{F}$ have also set up a joint working group on quality. The audit section in the $B M \mathcal{F}$ will end in February 1992, but the journal will continue to carry papers on audit in its other sections.

Quality in Health Care will aim to explore all aspects of quality and the difficulties associated with improving it; look at the contributions of received opinion and scientific evidence as constituents of good practice; examine issues of quality from various perspectives - including patients'; monitor and reflect the wider effects of medical and clinical audit; and publish research on outcomes. The journal will thus contain original work and reviews and educational material. We want to help build the academic base for clinical audit. Papers we are seeking include those on measuring quality and outcome and those reporting on the appropriateness and effectiveness of clinical interventions.

To be relevant the journal must cover all the disciplines of medicine and extend beyond medicine. Thus associate editors include doctors from medical and surgical specialties, obstetrics, general practice, and public health; the director of the Royal College of Nursing's standards of care project; and a district general manager. The editorial board covers an even wider range, including experts from other health professions and countries other than Britain and lay people. It is one of the 
failures of the NHS that the various professional groups have remained primarily in their tribes (not least in their reading habits), and we want this to be a journal that will be useful to all groups.

Audit Specialist and Respiratory Physician and
Editor of Quality in Health Care,

FIONA MOSS

Central Middlesex Hospital, London NW10 7NS

Editor, $B M \mathcal{F}$
1 Department of Health. Medical audit in the hospital and community health services. London: DoH 1991. ( $\mathrm{HC}(91) 2$

2 Department of Health. Medical audit in the family practitioner services. London: DoH, 1990 $(\mathrm{FP})(90) 8$

3 Lyons C, Gumpert R. Medical audit data: counting is not enough. B.MF 1990;300:1563-6.

4 Smith T. Medical audit. BMF 1990;300:65.

5 Nixon SJ. Defining essential hospital data. BMF 1990;300:380-1.

6 Bell D, Layton AJ, Gabbay J. Use of a guideline based questionnaire to audit hospital care of acute asthma. BMF 1991;302:1440-3.

7 Berwick DM. Continuous improvement as an ideal in health care. N Engl f. Med 1989;320:53-6. 8 Berwick DM, Godfrey AB, Roessner J. Curing health care: new' strategies for quality improzement. San Francisco: Jossey-Bass, 1991

9 Irvine D. Managing for quality in general practice. London: King's Fund Centre, 1990.

10 Smith R. Medicine's need for kaizen. BM7 1990;301:679-80.

\title{
Is rheumatoid arthritis an infectious disease?
}

\author{
An epidemic would answer the question
}

Unlike most common chronic diseases, little is known about the aetiology of rheumatoid arthritis. Given the concordance rate in monozygotic (identical) twins, any genetic component is unlikely to be greater than $30 \%,{ }^{12}$ and no obvious environmental factors exist to explain the remaining $70 \%$. A viral cause seems the most likely. Infections with viruses, such as parvovirus, ${ }^{3}$ result in inflammatory polyarthritides indistinguishable from rheumatoid arthritis, but seroepidemiological and other studies have failed to confirm a role for parvovirus or, indeed, other viruses in series of patients with rheumatoid arthritis. ${ }^{4-6}$ The identification of Borrelia burgdorferi as the causative agent for Lyme disease, ${ }^{7}$ which was initially considered to be an epidemic form of juvenile rheumatoid arthritis, accelerated the search for a microbiological cause for adult rheumatoid arthritis.

Unlike Lyme arthritis, no clusters of rheumatoid arthritis have been reported. Indeed, in familial clusters - in which a shared environmental insult might be expected to play a part - the calendar year of onset of disease in affected sibling pairs agreed no more often than in pairs of sporadic cases. ${ }^{9} 10$ No geographically defined populations exist with an exceptionally high incidence of the disease. Rheumatoid arthritis is rare in rural dwelling South African black people ${ }^{11-13}$ compared with urban dwellers. ${ }^{14}$ Urbanisation, being a proxy for overcrowding and perhaps for greater exposure to infectious diseases, may therefore be a risk factor.

The most striking observation about the geographic distribution of rheumatoid arthritis, however, is the similar prevalences reported in many different populations despite the diverse methods used. ${ }^{15}$ Few organisms, with the notable exception of Epstein-Barr virus, are sufficiently ubiquitous to explain this geographic pattern. Possibly relevant is the similar geographic distributions of rheumatoid arthritis and infectious mononucleosis. ${ }^{16}$

A potentially more rewarding line of inquiry has been the search for time trends in a population. The evidence suggests that rheumatoid arthritis has been declining in both incidence and severity. ${ }^{17} 18$ Thus population based studies of cases in both the United States ${ }^{1920}$ and the United Kingdom ${ }^{21}$ support a decline in incidence in the past 25 years, mirroring the anecdotal impression of rheumatologists. ${ }^{23}$ Similarly anecdotal evidence exists for a decline in severity-for example, as judged by the occurrence of vasculitis ${ }^{2+}$ - though data are limited. Successive generations of patients with rheumatoid arthritis seem increasingly less likely to be positive for rheumatoid factor or to have erosive disease or subcutaneous nodules. ${ }^{25}$ Mortality, particularly in older women, may be declining, ${ }^{26}$ though whether this reflects trends in incidence, severity, or certifying death is unclear. More persuasive is the direct observation that follow up of similarly composed groups of patients has shown a fall in the rate of those progressing to severe handicap over the past 25 years. ${ }^{2327}$

These observations are obviously compatible with several explanations. The decline in severity could be explained by more effective treatment, although limited evidence exists for any of the currently available treatments improving the long term prognosis sufficiently to have an impact on populations. The apparent decline in incidence could be due to changes in diagnostic practice with the application of more rigid criteria. Such a phenomenon, however, would not be consistent with any decline in severity.

Twenty years ago it was postulated that the improvement in atmospheric pollution, perhaps mediated by a reduction in the incidence of respiratory infections, was responsible for the reduction in the prevalence of rheumatoid factor in the population. ${ }^{28}$ Others have argued more recently that the temporal patterns of rheumatoid arthritis are consistent with a similar cyclic change in the epidemicity and virulence of specific, but as yet unknown, micro-organisms. ${ }^{2429}$ The conclusion remains that a viral cause for rheumatoid arthritis in genetically susceptible people is the strongest candidate. In the absence of further leads from the laboratory all epidemiologists can do is wait with their bags packed for the call to investigate an apparent epidemic.

\section{Director,}

ALAN J SILMAN

ARC Epidemiology Research Unit,

Stopford Building,

University of Manchester,

Manchester M13 9PT

1 Lawrence JS. Rheumatoid arthritis-nature or nurture? Ann Rheum Dis 1970;29:357-79.

2 Aho K, Koskenvuo M, Tuominen J, Kaprio J. Occurrence of rheumatoid arthritis in a nationwide series of twins. I Rheumatol 1986;13:899-902.

3 Naides SJ, Scharosch LL, Foto F, Howard EJ. Rheumatologic manifestations of human parvovirus B19 infection in adults. Arthritis Rheum 1990;33:1297-309.

4 Cohen BJ, Buckley MM, Clewley JP, Jones VE, Puttick AH, Jacoby RK, et al. Human parvovirus infection in early rheumatoid and inflammatory arthritis. Ann Rheum Dis 1986;45:832-8.

5 Ferrell PB, Aitchesion CT, Pearson GR, Tan EM. Seroepidemiological study of relationships between Epstein-Barr virus and rheumatoid arthritis. $\mathcal{F}$ Clin Invest 1981;67:681-7.

6 Venables PJW, Ross MGR, Charles PJ, Melsom RD, Griffiths PD, Maini RN, et al. A seroepidemiological study of cytomegalovirus and Epstein-Barr virus in rheumatoid arthritis and sicca syndrome. Ann Rheum Dis 1985;44:742-6.

7 Steere AC, Grodzicki RL, Kornblatt AN, Craft JE, Barbour AG, Burgdorfer W, et al. The spirochetal etiology of Lyme disease. N Engl F Med 1983;308:733-9.

8 Steere AC, Malawista SE, Hardin JA, Snydman DR, Chope RE, Andiman WA, et al. An epidemic of oligoarticular arthritis in children and adults in three Connecticut communities. Arthritis Rheum 1977;20:7-37.

9 Silman AJ, Ollier WER, Currey HLF. Failure to find disease similarity in sibling pairs with rheumatoid arthritis. Ann Rheum Dis 1987;46:135-8.

0 Sanders PA, Grennan DM. Age and year of onset differences in siblings with rheumatoid arthritis. Br J Rheumatol 1990;29:128-30.

11 Beighton P, Soloman L, Valkenburg HA. Rheumatoid arthritis in a rural South African negro population. Ann Rheum Dis 1975;34:136-41.

12 Meyers OL, Daynes G, Beighton P. Rheumatoid arthritis in a tribal Xhosa population in the Transke. Ann Rheum Dis 1977;36:62-5.

13 Brighton SW, de la Harpe AL, van Staden DJ, Badenhorst JH, Myers OL. The prevalence of rheumatoid arthritis in a rural African population. I Rheumatol 1988;15:405-8.

14 Soloman L, Robin G, Valkenburg HA. Rheumatoid arthritis in an urban South African negro Soloman L, Robin G, Valkenburg HA. Rhe
population. Ann Rheum Dis 1975;34:128-35.

15 Spector TD. Rheumatoid arthritis. Rheum Dis Clin North Am 1990;16:513-37. 